\title{
ASSESSMENT OF CONSTITUTIVE MODEL FOR ULTRA-HIGH PERFORMANCE FIBER REINFORCED CEMENT COMPOSITES WITH THE BARCELONA TEST
}

\author{
A. Blanco (1), S.H.P. Cavalaro (1), E. Galeote (1) and A. Aguado (1) \\ (1) Universitat Politècnica de Catalunya-BarcelonaTech, (Spain)
}

\begin{abstract}
The characterization of the post-cracking behavior of fiber reinforced cement composites (FRCC) represents a great challenge given the intrinsic scatter of the material and the need to use testing methods that are reliable and representative of the real-scale structure. The Barcelona test emerged as an alternative to other traditional testing methods that exhibit significant scatter and that are complex in terms of execution. Recently, a constitutive model analytically derived from the Barcelona test was developed and validated for conventional FRCC. The Barcelona test and the constitutive model combined provide a powerful tool for the design of this type of structures. Nevertheless, the applicability of this model to reproduce high and ultra-high performance FRCCs was not verified yet. The present study aims to validate the model by simulating the Barcelona test through finite element analysis and comparing the results with the experimental data obtained from steel and glass fibers mixes. In addition, the constitutive model derived of the Barcelona test is compared to the one included in the Model Code 2010, which is obtained through flexural tests of beams.
\end{abstract}

Keywords: constitutive model, Barcelona test, ultra-high performance fiber reinforced cement composites, design, finite element method

\section{INTRODUCTION}

The Barcelona test [1] or double punch test is a simple and reliable method to assess the post-cracking behavior of fiber reinforced cement composites Until recently, its use for design purposes was hindered by the lack of a constitutive models derived directly from the results of the test. This may be partially attributed to the difficulty of considering the change of the resistant mechanism that occurs during the fracture process observed during the test [2]. In fact, the expressions reported in the literature concern formulations to determine single values of the tensile strengths [3-6], which are also assumed for the post-cracking stage.

An analytical formulation was recently proposed to estimate the tensile constitutive curve of FRCC from the results of the Barcelona test. This formulation takes into account the change in the resistant mechanism, thus being valid for both the linear-elastic and postcracking stages [7]. Although it was validated for conventional performance FRCC, the 
reliability for the case of ultra-high performance FRCC (UHPFRCC) was not evaluated. This is relevant since UHPFRCC might present a pronounced hardening after cracking.

This paper aims to ascertain the reliability of the constitutive model for its application to UHPFRCC through experimental and numerical studies. On one hand, specimens with steel fibers and glass fibers were produced and characterized with the Barcelona test and the flexural test EN14651:2005 [8]. The constitutive models obtained by applying the formulation for the Barcelona test are compared with the one obtained by using the results of the bending test and the equation proposed in the Model Code 2010 [9]. On the other hand, the Barcelona test is simulated numerically through a finite element analysis and the load-displacement diagrams yielded by the analysis are compared to the results of the experimental program.

\section{CONSTITUTIVE MODEL}

The constitutive model derived from the Barcelona test [7] is an analytical formulation deduced from the resistant mechanisms observed during the test. The expression to estimate the tensile stress $(\sigma)$, presented in equation (1), was obtained applying balance of forces among the conical wedge and the concrete segments formed after the cracking. Notice that $F_{P}$ is the force applied by the press through the plate, $\beta$ is the failure angle of the material, which depends on the interlocking effect between the aggregates and the fibres crossing the contact surface, and $\mu_{k}$ corresponds to the kinetic friction coefficient. In this case, $\mu_{k}$ should be used since the conical wedge is constantly moving during the test. The parameter $A$ represents the area of the sectional cut of one quarter of the specimen subtracted by the sectional area of half of one conical wedge, which is not part of the cracked surface, as indicated in equation (2).

The expression to estimate the strain $(\varepsilon)$ was derived using the theory of the virtual works and assuming that the lateral displacement of the concrete sections is equivalent to the circumferential deformation of a theoretical specimen that it is not allowed to have radial cracks [7]. Considering this, $\varepsilon$ may be estimated through equation (3), where $n$ represents the number of cracks, $\Delta \delta_{P}$ is the displacement of the wedges due to the load applied by the plate and $R$ is the radius of the specimen (for standard specimens $R=150 \mathrm{~mm}$ ).

$$
\begin{aligned}
& \sigma=\frac{F_{P}}{2 \cdot \pi \cdot A} \cdot \frac{\cos \beta-\mu_{k} \cdot \sin \beta}{\sin \beta+\mu_{k} \cdot \cos \beta} \\
& A=\frac{d \cdot h}{4}-\frac{d^{\prime 2}}{4 \cdot \tan \beta} \\
& \Delta \varepsilon=\frac{n \cdot \Delta \delta_{P}}{\pi \cdot R} \cdot \tan \beta \cdot \sin \left(\frac{\pi}{n}\right)
\end{aligned}
$$

\section{EXPERIMENTAL PROGRAM}

In order to validate the formulation and to compare it with the constitutive model in the Model Code 2010, an experimental program involving Barcelona tests and 3-point bending tests was conducted. Two concrete mixes (M1 and M2) were produced with steel fibers (SF) and glass fibers (GF), respectively. The fiber content in each case corresponds to $1.9 \%$ and $1.6 \%$ in terms of the total volume. The details of the concrete mixes are presented in Table 1 and the main characteristics of the SF and the GF employed are included in Table 2. 
Table 1: Concrete mixes.

\begin{tabular}{|c|c|c|c|}
\hline Component & Characteristics & M1 $\left(\mathrm{kg} / \mathrm{m}^{3}\right)$ & M2 $\left(\mathrm{kg} / \mathrm{m}^{3}\right)$ \\
\hline Cement & $52,5 \mathrm{R}$ & 800 & 800 \\
\hline Sand $0 / 2$ & Silica & 1161 & 1161 \\
\hline Filler & Betoflow $\left(\mathrm{CaCO}_{3}\right)$ & 200 & 200 \\
\hline Filler & Nano-silica & 40 & 40 \\
\hline Water & - & 228 & 236 \\
\hline Admixture & Superplastifier (Powerflow) & 30 & 30 \\
\hline Fibers & Steel / Glass & 150 & 44 \\
\hline
\end{tabular}

Table 2: Characteristics of the fibers.

\begin{tabular}{|l|l|l|l|l|l|}
\hline Fiber & $\begin{array}{l}\text { Length } \\
\mathbf{( m m )}\end{array}$ & $\begin{array}{l}\text { Diameter } \\
\mathbf{( m m )}\end{array}$ & $\begin{array}{l}\text { Tensile strength } \\
\mathbf{( M P a )}\end{array}$ & $\begin{array}{l}\text { Modulus of } \\
\text { elasticity } \mathbf{( G P a )}\end{array}$ & $\begin{array}{l}\text { Specific weight } \\
\left(\mathbf{g} / \mathbf{c m}^{\mathbf{3}} \mathbf{)}\right.\end{array}$ \\
\hline SF & 13 & 0.2 & $2300-2500$ & 210 & $7.75-8.05$ \\
\hline GF & 13 & 0.018 & 1400 & 74 & 2.7 \\
\hline
\end{tabular}

For the assessment of the mechanical properties of the M1 and M2, cubic specimens of 150 x 150 x $150 \mathrm{~mm}$, cylindrical specimens of $\phi 150$ x $300 \mathrm{~mm}$, cylindrical specimens of $\phi 150 \times$ $150 \mathrm{~mm}$ and beams of $150 \times 150 \times 600 \mathrm{~mm}$ were cast. After the mixing, the concrete was directly poured into the molds (see Figure 1a). In order to avoid plastic shrinkage a curing layer was applied in the free surface of the molds (see Figure 1b). After 24 hours of the manufacturing the specimens were demolded and transported to the Laboratory of Structure Technology Luis Agulló at UPC, where they were stored in a curing room at a temperature of $20^{\circ} \mathrm{C}$ and a relative humidity of $100 \%$.
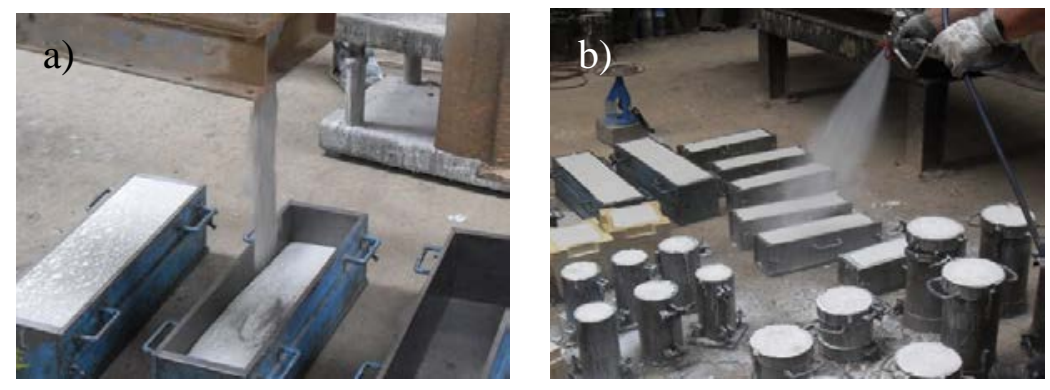

Figure 1: a) Filling of the molds and b) application of curing layer.

Compression tests (UNE12390-3:2009 [10]), modulus of elasticity tests (UNE83316:1996 [11]) and flexural tests (UNE83515:2010 [1]) were conducted to characterize the mixes. Table 3 presents the average values obtained from testing 4 specimens for compression and modulus of elasticity tests and 6 beams for the flexural test. The results show a higher compressive strength of mix M1 reaching typical values of UHPFRCC; whereas mix M2 remains in the range of high performance FRCC (HPFRCC) with a value 28.4\% lower. The residual strengths are significantly higher in the case of M1, which could be expected given the properties of the SF employed in M1, and the scatter is lower than for M2. 
Table 3: Average mechanical properties of the mixes.

\begin{tabular}{|c|c|c|c|c|c|c|c|c|c|c|c|c|}
\hline \multirow{3}{*}{ Fiber } & \multirow{2}{*}{\multicolumn{2}{|c|}{$\begin{array}{l}\begin{array}{l}\text { Modulus of } \\
\text { elasticity }\end{array} \\
E_{c m}\end{array}$}} & \multirow{2}{*}{\multicolumn{2}{|c|}{$\begin{array}{l}\text { Compressive } \\
\text { strength }\end{array}$}} & \multicolumn{8}{|c|}{ Residual flexural strengths } \\
\hline & & & & & \multicolumn{2}{|l|}{$f_{R 1}$} & \multicolumn{2}{|l|}{$f_{R 2}$} & \multicolumn{2}{|l|}{$f_{R 3}$} & \multicolumn{2}{|l|}{$f_{R 4}$} \\
\hline & $\begin{array}{l}\text { Avg. } \\
\text { (MPa) }\end{array}$ & $\begin{array}{l}\text { CV } \\
(\%)\end{array}$ & $\begin{array}{l}\text { Avg. } \\
(\mathrm{MPa})\end{array}$ & $\begin{array}{l}\text { CV } \\
(\%)\end{array}$ & $\begin{array}{l}\text { Avg. } \\
\text { (MPa) }\end{array}$ & $\begin{array}{l}\text { CV } \\
(\%)\end{array}$ & $\begin{array}{l}\text { Avg. } \\
\text { (MPa) }\end{array}$ & $\begin{array}{l}\text { CV } \\
(\%)\end{array}$ & $\begin{array}{l}\text { Avg. } \\
\text { (MPa) }\end{array}$ & $\begin{array}{l}\text { CV } \\
(\%)\end{array}$ & $\begin{array}{l}\text { Avg. } \\
\text { (MPa) }\end{array}$ & $\begin{array}{l}\mathrm{CV} \\
(\%)\end{array}$ \\
\hline M1 & 34971 & 3.16 & 102.79 & 1.54 & 22.59 & 8.77 & 21.61 & 8.96 & 17.96 & 9.26 & 15.2 & 8.75 \\
\hline M2 & 31137 & 2.72 & 73.59 & 3.14 & 9.19 & 9.81 & 3.41 & 11.43 & 1.63 & 12.72 & 1.06 & 13.11 \\
\hline
\end{tabular}

\section{NUMERICAL VALIDATION}

\subsection{Model type and geometry}

The Barcelona test was modeled with the finite element software DIANA 9.4, which presents extensive material library and analysis capabilities, performing a 3D analysis and using solid and interface elements to reproduce the behavior of the specimen. Given the symmetry of the test, only half of the specimen was modeled to favor the efficiency of the analysis and a more refined mesh discretization. The load was directly applied in an equivalent area to that of the steel punch used in the test on the top surface of the specimen.

The change of the resistant mechanism during the fracture process precludes the use of a single mesh to reproduce all the volume of the specimen. Such approach would entail localized large displacement at certain locations (particularly in the formation of the cone) that may cause divergences and a different response from the real one. Hence, the specimen was addressed as the summation of the conical wedge and the rest of the specimen. The approach of predefining the failure mechanism in a double punch test was already applied in previous studies [12]. In order to avoid concentrated loads in the vertex, the cone was approximated as an inverted truncated cone with a top diameter equal to that of the steel punch, a bottom diameter of $4 \mathrm{~mm}$ and a height of $40 \mathrm{~mm}$.

An interface element defined between the lateral surfaces of the cone and the specimen allows the displacement of the cone and the cracking. In order to reduce the influence that the discretization adopted may have on the mesh and the results, the meshes of each of the 4 parts of the specimen were radially generated. The vertical displacement of the bottom face was restrained to ensure the symmetry conditions. The load case consisted in a vertical displacement acting simultaneously at all nodes on the loading surface. Each load step was equivalent to a vertical displacement of $0.025 \mathrm{~mm}$.

\subsection{Material properties}

In the simulation of the specimens, a fracture energy based on total strain rotating crack model [13] was considered. Given that cracking is not expected in the cone, as experimentally verified, elastic properties were assumed with a modulus of elasticity equal to that of the corresponding mixes. The interface material between the cone and the rest of the specimen was characterized by a linear normal and linear tangential stiffness and a frictional behaviour simulated using a Coulomb friction model with a brittle gapping criterion.

The constitutive models were simplified to a multilinear model defined by four points, which facilitates the input in DIANA. The values of tensile and residual strengths were obtained by considering the $\beta=0.438$ rad and $n=3$. In the absence of reliable values of $\mu_{k}$, the $\mu_{\mathrm{s}}$ proposed in the Model Code 2010 was used. Considering the aspect of the conical wedge after the test, it was assumed that the $\mu_{s}$ should be in the range of rough surfaces but it 
was reduced to take into account the smoothening of the surface while it penetrates inside the specimen. Hence, a $\mu_{k}=0.7$ is considered a reasonable initial approximation. It is important to remark that more studies are required to characterize $\mu_{k}$ and the variables affecting this parameter. The material properties used in the model associated to each specimen are summarized in Table 4.

Table 4: Material properties considered in the FEM model.

\begin{tabular}{|c|c|c|c|}
\hline Model part & Material properties & Value & Reference \\
\hline \multirow{4}{*}{$\begin{array}{r}\text { Interface } \\
\text { material }\end{array}$} & Normal stiffness $\left[\mathrm{MN} / \mathrm{m}^{3}\right]$ & $1.0 \cdot 10^{5}$ & \\
\hline & Tangential stiffness $\left[\mathrm{MN} / \mathrm{m}^{3}\right]$ & $1.0 \cdot 10^{5}$ & \\
\hline & Tangent friction angle & 0.7 & \\
\hline & Tangent of dilatancy angle & 0.0 & \\
\hline \multirow[b]{2}{*}{$\begin{array}{l}\text { Conical } \\
\text { wedge }\end{array}$} & Poisson ratio $[-]$ & 0.2 & \\
\hline & Average modulus of elasticity [GPa] & $\begin{array}{l}35.3 / 33.6 / 34.7 / 36.3 \\
31.9 / 30.0 / 31.6 / 31.1\end{array}$ & $\begin{array}{l}\text { M1_1/M1_2/M1_3/M1_4 } \\
\text { M2_1/M2_2/M2_3/M2_4 }\end{array}$ \\
\hline \multirow{11}{*}{ M1 \& M2 } & Compressive strength[MPa] & $\begin{array}{l}\text { 103.4/100.6/104.3/102.9 } \\
76.7 / 71.7 / 73.9 / 72.0\end{array}$ & $\begin{array}{l}\text { M1_1/M1_2/M1_3/M1_4 } \\
\text { M2_1/M2_2/M2_3/M2_4 }\end{array}$ \\
\hline & Modulus of elasticity [GPa] & $\begin{array}{l}35.3 / 33.6 / 34.7 / 36.3 \\
31.9 / 30.0 / 31.6 / 31.1\end{array}$ & $\begin{array}{l}\text { M1_1/M1_2/M1_3/M1_4 } \\
\text { M2_1/M2_2/M2_3/M2_4 }\end{array}$ \\
\hline & Poisson ratio [-] & 0.2 & Eurocode $2[14]$ \\
\hline & Tensile strength $\sigma_{1}[\mathrm{MPa}]$ & $\begin{array}{l}4.96 / 5.03 / 5.05 / 4.86 \\
4.11 / 3.79 / 3.93 / 4.05\end{array}$ & $\begin{array}{l}\text { M1_1/M1_2/M1_3/M1_4 } \\
\text { M2_1/M2_2/M2_3/M2_4 }\end{array}$ \\
\hline & Residual strength $\sigma_{2}[\mathrm{MPa}]$ & $\begin{array}{l}4.89 / 4.99 / 5.05 / 4.78 \\
3.12 / 3.22 / 1.98 / 2.85 \\
\end{array}$ & $\begin{array}{l}\text { M1_1/M1_2/M1_3/M1_4 } \\
\text { M2_1/M2_2/M2_3/M2_4 }\end{array}$ \\
\hline & Residual strength $\sigma_{3}[\mathrm{MPa}]$ & $\begin{array}{l}2.66 / 2.32 / 3.29 / 3.94 \\
0.46 / 0.70 / 0.50 / 0.82\end{array}$ & $\begin{array}{l}\text { M1_1/M1_2/M1_3/M1_4 } \\
\text { M2_1/M2_2/M2_3/M2_4 }\end{array}$ \\
\hline & Residual strength $\sigma_{4}[\mathrm{MPa}]$ & $\begin{array}{l}1.57 / 1.32 / 2.15 / 2.29 \\
0.12 / 0.15 / 0.13 / 0.20\end{array}$ & $\begin{array}{l}\mathrm{M} 1 \_1 / \mathrm{M} 1 \_2 / \mathrm{M} 1 \_3 / \mathrm{M} 1 \_4 \\
\mathrm{M} 2 \_1 / \mathrm{M} 2 \_2 / \mathrm{M} 2 \_3 / \mathrm{M} 2 \_4\end{array}$ \\
\hline & Strain $\varepsilon_{1}[\%$ o] & $\begin{array}{l}0.14 / 0.15 / 0.15 / 0.13 \\
0.13 / 0.13 / 0.12 / 0.13\end{array}$ & $\begin{array}{l}\text { M1_1/M1_2/M1_3/M1_4 } \\
\text { M2_1/M2_2/M2_3/M2_4 }\end{array}$ \\
\hline & Strain $\varepsilon_{2}[\%$ o] & $\begin{array}{l}0.24 / 0.25 / 0.25 / 0.23 \\
0.23 / 0.23 / 1.00 / 0.23\end{array}$ & $\begin{array}{l}\text { M1_1/M1_2/M1_3/M1_4 } \\
\text { M2_1/M2_2/M2_3/M2_4 }\end{array}$ \\
\hline & Strain $\varepsilon_{3}[\% o]$ & $\begin{array}{l}5.50 / 10.00 / 4.00 / 4.00 \\
1.50 / 2.50 / 5.00 / 2.50\end{array}$ & $\begin{array}{l}\text { M1_1/M1_2/M1_3/M1_4 } \\
\text { M2_1/M2_2/M2_3/M2_4 }\end{array}$ \\
\hline & Strain $\varepsilon_{4}[\%$ o $]$ & $\begin{array}{l}20.00 \\
6.00 / 7.00 / 15.00 / 12.50\end{array}$ & $\begin{array}{l}\text { M1_1/M1_2/M1_3/M1_4 } \\
\text { M2_1/M2_2/M2_3/M2_4 }\end{array}$ \\
\hline
\end{tabular}

\subsection{Results}

Figure 2 shows the experimental and the estimated curves for each specimen. It must be remarked that an accommodation effect is observed in the test between the surfaces of the piston and the specimen (due to irregularities of its surface) that leads to larger displacements in the early stages. This effect was not observed in the simulation since the contact is perfect from the beginning of the test. For this reason, the maximum load of the experimental curve was moved to match the peak of the simulated curve.

Significant differences are observed between the specimens from M1 and M2, which may be attributed to the material properties of each fiber (see Table 2). Regarding the accuracy of the model, the first aspect to highlight is the estimation of the peak load for both mixes. Figures 2a, 2b, 2c and 2d show that the model yields satisfactory results for M1 in this regard, being in all cases the difference between the estimated peak load and the real one lower than $5 \%$. Nevertheless, Figures 2e, 2f, $2 \mathrm{~g}$ and $2 \mathrm{~h}$ indicate that for M2 the difference is significantly higher. In fact, in average the model underestimates the real value in $65 \%$. 

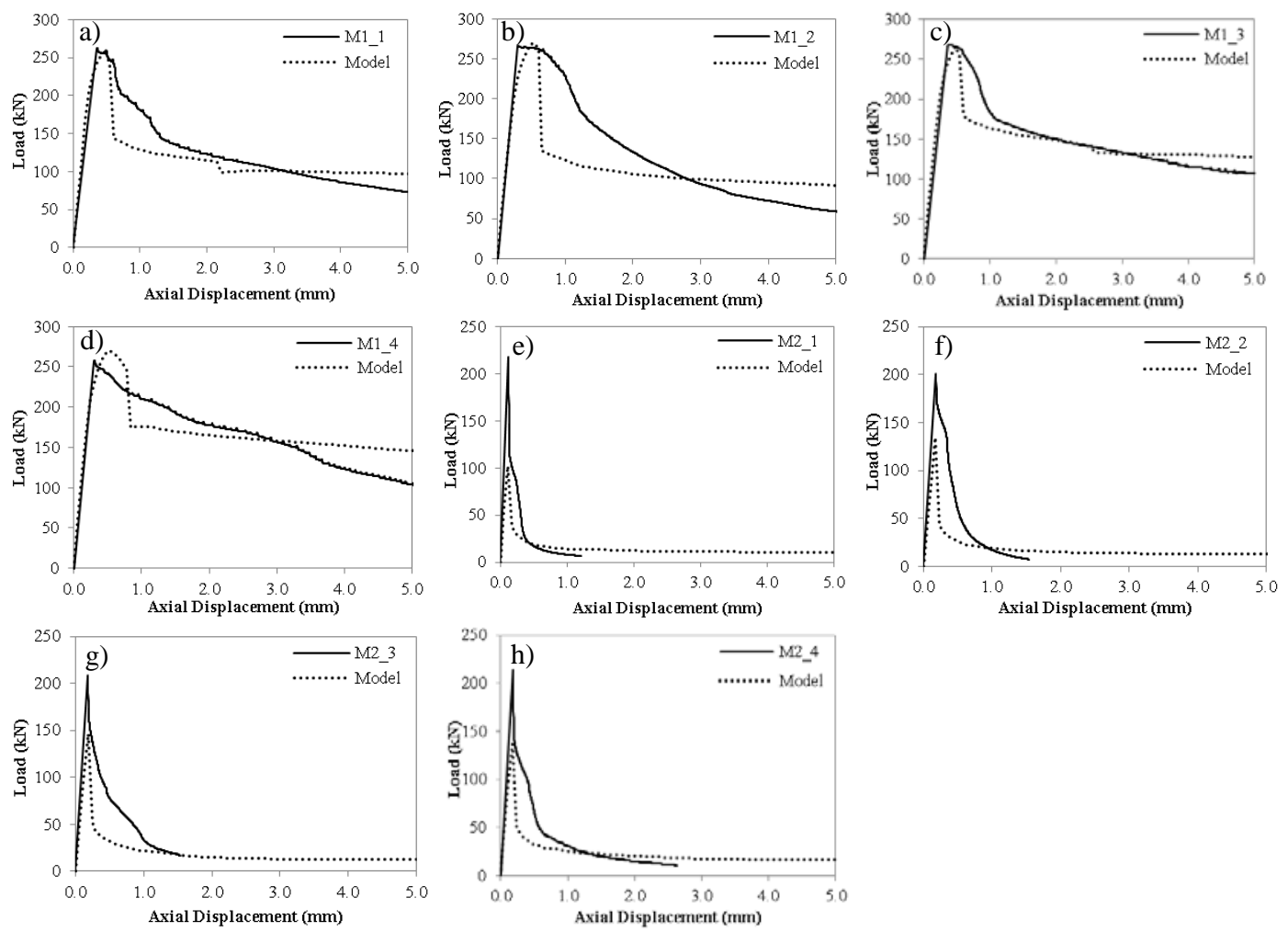

Figure 2: Experimental and estimated curves of the Barcelona test: a) M1_1, b) M1_2, c) M1_3, d) M1_4, e) M2_1, f) M2_2, g) M2_3 and h) M2_4.

Besides the peak load, a general overview of the curve reveals that the finite element model does not reproduce accurately the behavior of the specimens immediately after the cracking occurs. In general, the model yields curves with a sudden drop of load that does not fit the experimental results. This is particularly evident in the specimens of mix M1, which in fact do not exhibit the sudden drop of load. In the case of the specimens of mix M2, this phenomenon occurs but to a lesser degree than in the curves yielded by the models. Such outcome was already observed in the assessment of the formulation for conventional FRCC [7]. In fact, the authors believe this may be partially attributed to the limitations of the finite element models to reproduce the change of failure mechanism during the test.

Nonetheless, the novelty of the formulation is its applicability to estimate the post-cracking stage of the material, therefore the aim of the finite element analysis is to validate that stage of the experimental data. In this sense, the results indicate that in general the estimations present a similar tendency in terms of order of magnitude of the load and shape of the curve to the real behavior observed in the laboratory. However, the differences in the load observed for small values of displacement are still significant in some cases (see Figures 2b, 2e, $2 \mathrm{f}$ and $2 \mathrm{~g}$ ). Despite that, the model remains from the safety side since the values provided are lower than the real ones. As the displacement increases, the experimental and estimated curves tend to converge. The results confirm that the constitutive model is capable to estimate the response of the UHPFRCC. However, it is also evident that the simulation of the behavior immediately after the cracking still remains an issue and needs to be further assessed. 


\section{COMPARISON WITH MODEL CODE 2010}

The constitutive model derived from the Barcelona test is compared in Figure 3 with the constitutive model included in the Model Code 2010 [9], which was selected among the several European codes and recommendations since it is the most recently proposed constitutive model and it provides a hardening behavior curve. It should be remarked that the values correspond to the average of all the specimens of M1 and M2. Likewise, partial safety factors were not used to obtain any values of stress and strain. The notation used to refer the models is MC and BCN for the Model Code 2010 and the Barcelona test, respectively.
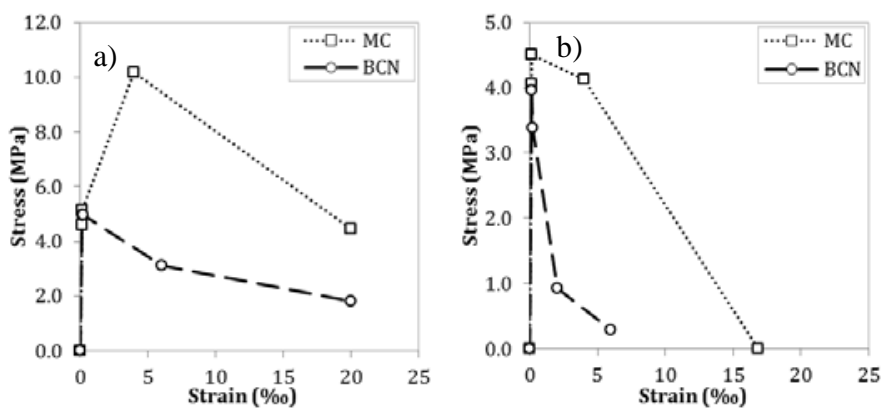

Figure 3: Comparison between MC and BCN constitutive models: a) M1 and b) M2.

The curves indicate that the MC constitutive model derived from the flexural performance of small beams exhibits higher values of stress and, in the case of M2, also a higher ultimate strain. These differences between the two models are bigger than the ones observed in previous studies for conventional FRCC [7]. Notice that for the stress associated to the ultimate strain in the mix M1, the value provided by the MC model is $143 \%$ higher than the value obtained with the BCN model. In fact, the MC models present a hardening behavior that is not observed in the BCN model. This is related to the amount of energy dissipated during the test, which is around 4-5 times bigger than in the beam test [14] due to its bigger cracking surface. Since the energy dissipated in the beam test is smaller and less abrupt, it is possible that for the same fiber content the beam test exhibits a hardening behavior, whereas in the Barcelona test this content is not enough to generate a restriction high enough to avoid the sliding of the wedge into the specimen, thus reaching a hardening response of the material.

The results from Figure 3 reveal that for a same material, different constitutive models may be obtained depending on the type of characterization test employed. This should not be unexpected given the differences in the failure mechanisms and fiber orientations in the beam and in the cylindrical specimen. This is of paramount importance since these results reinforce the need to select characterization tests that are representative of the element that is going to be designed both in terms of structural response and fiber orientation. According to this, the Barcelona test may be more appropriate for 2-D structures (e.g. slabs or plates) and the beam test may be more representative of 1-D structures such as beams. This concept is essential to develop rational and reliable design methods for UHPFRCC.

\section{CONCLUSIONS}

The study conducted confirms the applicability of the constitutive model derived from the Barcelona test to estimate the post-cracking response of HPFRCC and UHPFRCC mixes. Based on the results obtained, several specific conclusions may be drawn: 
- The capacity of the constitutive model to estimate the post-cracking stage of HPFRCC and UHPFRCC mixes was verified through the results of the numerical model, which yield curves in the same order of magnitude of the experimental data.

- Despite that, noticeable differences are observed in the response immediately after the cracking occurs. These differences may be partially attributed to the limitations of the FEM models to reproduce the complex phenomenon of the change in the failure mechanism that occurs in the Barcelona test.

- The comparison of the numerical results and the experimental data also reveals noticeable differences in the prediction of the peak load depending on the type of concrete mix.

- The constitutive models obtained with the Model Code 2010 and the Barcelona test present noticeable differences, which evidences the importance of selecting representative testing methods to obtain the constitutive model for the design.

\section{ACKNOWLEDGEMENTS}

The authors acknowledge the collaboration of ESCOFET S.A. in the performance of the experimental program. The third author expresses his gratitude for the support provided by the grant FPU of the Spanish Ministry of Education, Culture and Sports.

\section{REFERENCES}

[1] AENOR, 'UNE 83515:2010. Hormigones con fibras. Determinación de la resistencia a fisuración, tenacidad y resistencia residual a tracción. Método Barcelona', Asociación Española de Normalización y Certificación (Madrid, 2010).

[2] Pujadas, P., Blanco, A., Cavalaro, S., de la Fuente, A. and Aguado, A., 'New analytical model to generalize the Barcelona test using axial displacement', J. Civ. Eng. Manage. 19 (2) (2013) 259-71.

[3] Chen, W.F., 'Double punch test for tensile strength of concrete', ACI Mater. J. 67 (2) (1970) $993-5$.

[4] Bortolotti, L., 'Double-punch test for tensile and compressive strengths in concrete'. ACI Mater. J. 85 (1) (1988), 26-32.

[5] Chen, W. F. and Yuan, R. L., 'Tensile strength of concrete: double punch test', J. Struct. Div. 106 (8) (1980), 1673-93.

[6] Marti, P., 'Size effect in double-punch tests on concrete cylinders', ACI Mater. J. 86 (6) (1989), 597-601.

[7] Blanco, A., Pujadas, P., Cavalaro, S., de la Fuente, A. and Aguado, A. 'Constitutive model for fibre reinforced concrete based on the Barcelona test', Cement Concrete Comp. 53 (2014), 327-40.

[8] CEN, 'EN 14651:2005. Test method for metallic fibre concrete - measuring the flexural tensile strength (limit of proportionality (LOP), residual)', European Committee for Standardization (Brussels, 2005).

[9] fib, 'Model Code 2010', International Federation for Structural Concrete (Lausanne, 2010).

[10] CEN, 'EN 12390-3:2009. Testing hardened concrete - Part 3: Compressive strength of test specimens', European Committee for Standardization (Brussels, 2009).

[11] AENOR, 'UNE 83316:1996. Ensayos de hormigón. Determinación del módulo de elasticidad en compresión', Asociación Española de Normalización y Certificación (Madrid, 1996).

[12] Burgers, R., Walraven, J.C., Plizzari, G.A. and Tiberti, G., Structural behavior of SFRC tunnel segements during TBM operations. In: Barták, Hrdina, Romancov, Zlámal, editors. Proceedings of the underground space - the 4th dimension of metropolises: world tunnel congress 2007 and 33rd ITA/AITES annual general assembly, Prague, Czech Republic. Taylor \& Francis Group; 2007. P.1461-7.

[13] CEN, 'ENV 1992-1-1 Eurocode 2: design of concrete structures - Part 1: general rules and rules for buildings', European Committee for Standardization (Brussels, 1992).

[14] Guàrdia, J., 'Caracterització del comportament a tracció de formigó d’alta treballabilitat reforçat amb fibres d'hacer mitjançant l'assaig Barcelona', Bachelor thesis, Universitat Politlècnica de Catalunya, Barcelona, 2008 (In Catalan). 